in the sugar mills, bagasse could be released for kraft paper manufacture. Enormous amounts of this material, when available, are used in the bazaars of India. The Bulletin sets forth the methods by which bagasse can be utilized in the manufacture of kraft paper for wrapping purposes and for use in multiwall bags as substitutes for jute bags, and goes closely into the results of the laboratory and pilotplant tests on bagasse as a source of paper.

The wrapping-paper industry in India is still in its infancy. It was only in 1940 that production of kraft paper was commenced by two mills, based on the results of investigations carried out at the Forest Research Institute, Dehra Dun, on bamboos. Of the two mills, one stopped manufacturing kraft paper in 1942 , and the production of the other averages 25 . 30 tons a day, equivalent to $7,500-9,000$ tons a year. As against this, the imports of kraft paper by India (undivided) in the pre-war period were of the order of 13,000 tons a year, and of other varieties of wrapping paper approximately another 12,000 tons a year. There is little doubt that demand for kraft papers has considerably increased of late. In 1946 the Paper Panel appointed by the Government of India estimated that by 1951 the annual requirements of wrapping papers for India (undivided) was likely to be 80,000 tons, and by 1956 it would be 100,000 tons.

With the partition of India, many problems have had to be faced, and one of considerable importance is the shortage of jute, which is required for manufacture of bags used for packing sugar, cement, grains, etc. The sugar industry alone is estimated to require well over twelve million bags a year, and the cement industry needs approximately twice that number. Recently, sugar and cement factories have had to curtail or temporarily stop production owing to shortage of jute bags. In foreign countries, particularly in those which are rich in cellulosic materials, it has become a common practice to substitute multiwall paper bags for jute bags, and the former have successfully replaced the latter for numerous purposes.

\section{OIL INDUSTRIES EXHIBITION}

7 HE Shell Petroleum Company in association with the Anglo-Iranian Oil Company are holding this year an exhibition of the oil industry at a number of universities in Great Britain. The exhibition is concerned with all phases of the industry; but chief emphasis is laid on oilfield exploration and development. Its main purpose is educational and, although primarily of general university appeal, it is also aimed at attracting the interested public ; much care has been taken to present the more specialized aspects of the industry in as clear a manner as possible. It is fitting that the exhibition should emphasize oilfield exploration and development, the importance of which is not generally appreciated by those in Great Britain unfamiliar with the industry. It is in these fields that there has perhaps been the greatest development of new techniques in recent years, as a result of co-ordinated research in many branches of science in which academic research on fundamentals has played a large part.

The exhibition was opened on April 5 by Sir Henry Tizard, chairman of the Advisory Council on Scientific Policy, under the auspices of the Institute of Petroleum, in the Geology Department of the Royal School of Mines, London, S.W.7, where it will remain open until April 21. Afterwards it will move to the Royal
Technical College, Glasgow, during May 4-19, the University of Leeds, June 20-July 6, and the University of Cambridge, July 16-28. In opening the exhibition, Sir Henry spoke of the great economic importance of the oil industry and the need for maintaining its close association with the universities. Through technical efficiency the industry has met changing economic conditions with resource and enterprise.

Each visitor to the exhibition is provided with a guide which indicates the four main sections : oilfield exploration and development, transport, refining and manufacture, and distribution and products. The first part of the exploration and development section is an area display consisting of a series of attractively designed panels each illustrating oil operations in one of about twenty Commonwealth and foreign countries. As an introduction there is a large world map by Bip Pares, the well-known designer and economist, which shows the distribution of oilfields in the sedimentary basins of the world. In order to portray the great range of operations undertaken by oil companies at the present time, certain aspects have been chosen for display in each country : the Canadian panel, for example, emphasizes the important Alberta oil basin and includes a section across the basin showing the development of the oil-bearing coral reefs in this area. Other panels show such operations as : exploration in the tropics, the Trinidad Pitch Lake, and marine drilling off the coasts of Louisiana and Texas. On the Venezuelan panel the sociological influence of oilfield developments in remote areas is shown in a series of photographs of the new town of Cardon, which was built on a desert to provide amenities for refinery workers. From the point of view of local interest, there is a number of gravity and magnetic maps of southern England which have been prepared by the Anglo-Iranian Oil Co., and which are shortly to be published by the Geological Society.

The technical display which follows also consists of a series of panels presenting a comprehensive picture of the specialized techniques required in modern oilfield work. The fundamentals of geology and geophysics in relation to oilfield exploration are illustrated by a series of diagrams, and of especial interest is a chart showing the relative importance of technical surveys, in which the trends in geological and geophysical exploration methods during the past four decades are clearly shown. A series of coloured drawings outlines the current theory of the origin of petroleum, from the burial of organic material in fine-grained sediments and its transformation to oil, to the migration of the liquid petroleum to the reservoir rocks. Methods of exploration which are illustrated include aerial survey and photogeology, which are now widely used in the initial phases of exploration in unknown areas, and geophysical prospecting, which assists the geologist in the interpretation of subsurface geological structure by the application of physical methods at the surface.

The exploitation of an oilfield is illustrated by panels which show the drilling of oil wells by the rotary method, the techniques used in oilfield geological correlation, and problems related to the oil reservoir; in addition, there is a number of models and examples of oilfield equipment such as wellcasing, drilling bits, and a model derrick. In the early stage of development of an oilfield the determination of the geological structure of the oil reservoir is essential to the efficient planning of the complete development programmo, and a special exhibit 
demonstrates the various methods, both old and new, which are used to correlate geological formations from well to well, thus enabling the underground geological structure to be determined. A panel which discusses oil reservoir problems directs attention to one of the most important problems of the industry at the present time, that of producing all the oil contained within the reservoir rock; at the best, current production practice may recover only about 75 per cent of the oil originally stored within the reservoir.

The final sections on transport and refining, and distribution and products, also contains maps by Bip Pares, one of which, namely, that illustrating the world movement of oil in relation to tanker movements, is on an original projection. Of special interest is a series of photographs illustrating the construction of a pipe-line, and the cathodic protection methods employed to combat corrosion. A novel exhibit in the section on refining methods is a large coloured flow-chart which outlines the main refining processes, and of more specialized interest there is a number of smaller panels each illustrating in detail the stages of one refining process and including within the panels samples of the refined products. Another map shows the position of refineries in Great Britain and directs attention to the great development in refining that has taken place in the past five years. Chemical research in the industry is outlined on a panel which illustrates research in the laboratory and the use of petroleum derivatives for agricultural purposes.

As a final section of the exhibition, there are examples of the work of British manufacturers of oilfield equipment and a demonstration of the work of the Petroleum Information Bureau in the form of a display of leaflets and posters which discuss the various aspects of the industry.

Accompanying the exhibition three programmes of films are being shown daily under the auspices of the Petroleum Films Bureau, and in addition there is a special arrangement by which any film listed by the Bureau will be shown on request.

The oil companies are to be congratulated on a most interesting and informative exhibition, which not only well demonstrates the wide scope of the industry and the problems it is facing, but also serves to publicize the enterprise and achievements of British companies in the petroleum world.

C. A. Fothergili

\section{PROBLEMS OF THE NATIONALIZED INDUSTRIES OF GREAT BRITAIN}

$\mathrm{T}$

HE Acton Society Trust is issuing a series of papers in which an objective analysis of some of the problems of nationalized industry is attempted. The series* is edited by G. R. Taylor, and the first two pamphlets issued deal with "Accountability to Parliament" and with the "Powers of the Minister".

The first of these examines the reasons why Parliamentary control of the nationalized industries has not proved wholly satisfactory, and gives alternative or additional methods of supervision which might be employed. There is also appended an analysis of questions put in the House of Commons relating to

* Nationalized Industry Series : No. 1, Accountability to Parliament (pp. 33, 1950); No. 2, Powers of the Minister (pp. 20, 1951); No. 3, Problems of Promotion Policy (pp. 20, 1951). (Acton Suciety Trust, Acton House, Church Road, Claygate, Esher,
Surrey.) 2s. each. the nationalized industries. Briefly, Parliamentary control has been unsatisfactory because the flow of information to Parliament is inadequate and behindhand, and because members, in general, have not proved capable of assessing the highly technical problems involved and of pointing out with unanimous voice what is wrong. For Parliament to function more effectively, more frequent debates would be necessary and also attainment of a higher level in the debates, while Parliament would require more detailed information on which to base its judgment. A second alternative would be to transfer some part of the burden to a body other than Parliament. The pamphlet points out, however, that the question whether the public corporation is the most satisfactory means of operating nationalized industry should not be prejudged: the form of industrial ownership most consistent with social justice and public accountability may be of a different character altogether. More radical thinking is required, and a satisfactory solution is likely to be difficult while the principal political parties are sharply divided on the issue of nationalization itself.

The second pamphlet, after summarizing the statutory powers which have been given to the Ministers responsible for the newly nationalized industries and examining the use which has been made of those powers, discusses the proper role of the Minister with the view of determining what those powers should be. The conclusion is reached that the very extensive, not to say absolute, powers which the Ministers possess have been used with extreme caution, but that the situation is unsatisfactory because Parliament has developed no clear idea of the Minister's functions or of how close its supervision of the nationalized industries should be. That must be the first step towards a definite solution; but the present powers of Ministers appear to be somewhat excessive, and urgent consideration of the dispersal of some part of the Minister's powers among other bodies or persons and, where this is impossible, of the establishment of checks or balances, is recommended.

Whatever powers are left to the Minister, adequate safeguards have still to be created against a possible abuse of power. Some alarm is expressed, in par.ticular, at the Minister's power to prevent the disclosure of his own actions when, in his own opinion, it is not in the interests of security to do so, and surprise is expressed that any Parliament should have been prepared to assent to such a condition. The present situation, it is urged in this pamphlet, cannot be regarded with equanimity by those who are concerned with political freedom, even if the assumptions are made (none of which are above question) that industry must necessarily be operated on the national scale, that control must be largely centralized, that government itself must be highly centralized, and that commercial undertakings can best be supervised by a political body divided on party lines.

A third pamphlet in the same series, "Problems of Promotion Policy", brings out two grave dangers that procedures and policies in the nationalized industries present: first, the conflict between the desire for promotion by seniority and the need for a satisfactory standard of efficiency and service has not been faced; and secondly, there is a tendency to build up a rigid and elaborate system of regulations which both fails to secure justice and at the same time reduces efficiency and flexibility. 